\title{
TEMAS POLÍTICO-SOCIAIS NO ENSINO DA MATEMÁTICA
}

\section{Socio-political themes in Math's teaching}

\author{
Renata Ueno ${ }^{1}$ \\ Mara Sueli Simão Moraes ${ }^{2}$
}

Resumo: Este trabalho teve como objetivo propiciar condições para a aprendizagem de conceitos matemáticos e verificar se o conteúdo Estatística, abordado por meio da análise de tabelas e gráficos, trabalhado em grupos cooperativos, por intermédio da resolução de Problemas Ampliados por Temas Transversais/Político-Sociais, pode contribuir para a transformação do ensino e aprendizagem desse conteúdo e para a formação de seres humanos comprometidos com os aspectos políticos, culturais, sociais e ambientais da sociedade em que vivem.

Palavras-chave: Temas transversais/político-sociais. Grupos co-operativos. Problemas ampliados.

\begin{abstract}
The objective of this work is to enhance the conditions for the learning of mathematical concepts and to verify whether the statistics content, approached through the analysis of tables and graphics, worked in cooperative groups. Do the solution of problems in this context using Transverse Sociopolitical Themes, contribute to the transformation of the teaching and learning of these contents and to the formation of human subjects committed with the political, cultural, social and environmental features of the society where they live?
\end{abstract}

Key words: Transverses/social-political themes. Cooperative groups. Problems increased.

\footnotetext{
${ }^{1}$ Mestre em Educação para a Ciência; professora assistente, Faculdade de Tecnologia de Garça (FATEC). Garça, SP.<urenata@itelefonica.com.br>

${ }^{2}$ Doutora; professora, Departamento de Matemática; Programa de Pós-Graduação em Educação para a Ciência, Faculdade de Ciências, Universidade Estadual Paulista (Unesp), campus de Bauru. Bauru, SP.

<msmoraes@fc.unesp.br>

${ }^{1}$ Avenida Ricardo Travençolo, 123

Jardim Paulista - Garça, SP

17.400-000 


\section{Introdução}

Para que o trabalho nas salas de aula de matemática implique aprendizagem de conceitos, favorecendo a apropriação, por parte dos alunos, dos conhecimentos necessários à sua formação, torna-se indispensável aproximar os conteúdos matemáticos aos temas significativos do mundo atual e incluir questões vinculadas à realidade e interesse dos alunos.

Em nosso país, a partir de 1996, o Ministério da Educação e do Desporto deu início a uma reestruturação em seu sistema educacional, por meio da elaboração de documentos, como os Parâmetros Curriculares Nacionais (PCN), que chegaram às escolas "[...] com a intenção de ampliar e aprofundar um debate educacional que envolva escolas, pais, governo e sociedade, e dê origem a uma transformação positiva no sistema educativo brasileiro" (BRASIL, 1998, p. 5).

A Secretaria da Educação, por meio dos PCN, instituiu o trabalho com questões sociais a serem apresentadas para a aprendizagem dos alunos, com a mesma importância das áreas convencionais. Então, os temas transversais: ética, meio ambiente, trabalho e consumo, saúde, pluralidade cultural e orientação sexual, devem ser desenvolvidos em sala de aula, tendo a ética como eixo norteador, que leva à reflexão crítica e à construção da cidadania.

Uma forma de introduzir as questões políticas, sociais, culturais e ambientais no ensino da matemática, pode ser por meio da resolução de problemas ampliados que não envolvam apenas o conteúdo em si, mas a produção de significados referentes às questões abordadas. Para que isso ocorra, propomos, à luz do trabalho de outros educadores, uma mudança na estruturação dos conteúdos curriculares, colocando os temas transversais como eixos longitudinais do currículo. Moraes (2003, p. 204) coloca que os temas transversais são político-sociais,

[...] são o caminho ideal para a politização de nossos alunos, indo além do discurso dos PCN, na consecução de uma sociedade igualitária. São eles que permitem a apropriação de conceitos, mudanças de atitudes e procedimentos onde cada aluno participará de forma autônoma na construção e melhorias da comunidade em que se insere.

Eles devem ser trabalhados em todas as disciplinas, e não tratados como novos conteúdos a serem acrescentados aos já existentes, constituindo-se no centro das atuais preocupações sociais.

Esta pesquisa foi desenvolvida no ano de 2003, na E.E. Prof ${ }^{a}$. Nely Carbonieri de Andrade, na cidade de Garça - SP, aplicada em uma oitava série com quarenta alunos matriculados e que freqüentavam regularmente as aulas. Nosso objetivo foi verificar se a matemática, juntamente com temas transversais/político-sociais, pode contribuir para a formação de seres humanos comprometidos com a construção de uma sociedade justa.

Diante do desinteresse apresentado pelos alunos quanto ao trabalho em sala de aula, discutimos essa situação e decidimos, juntos, trabalhar pela mudança desse quadro. Os alunos passaram a trabalhar em grupos cooperativos, por meio de problemas ampliados que envolviam, além do conteúdo matemático, (no caso, a estatística), os temas político-sociais. Tudo isso, mediante um contrato de trabalho com regras estabelecidas entre a professora e os alunos, com o objetivo de melhor conduzir o andamento das atividades. 
Temas político-sociais no ensino da Matemática

Depois, por meio de nossas observações, fizemos uma avaliação a respeito da atuação dos alunos durante as aulas; dos trabalhos em grupos cooperativos desenvolvidos em sala; da análise dos seus apontamentos nas atividades, e com a aplicação de um questionário onde eles estabeleceram o que consideraram importante em sua aprendizagem. Todos estes dados, além das avaliações, em grupos e auto-avaliações, foram analisados de modo a buscar a resposta ao nosso questionamento.

\section{Referencial teórico}

Na psicologia, a teoria sociohistórica tem dado suporte teórico para estudos e pesquisas em diferentes áreas de ensino. Nessa teoria, o desenvolvimento humano, o aprendizado e as relações entre aprendizado e desenvolvimento são temas centrais, e ela busca compreender a origem e o desenvolvimento dos processos psicológicos ao longo da história da espécie humana.

Quanto à questão do aprendizado e desenvolvimento, Vygotsky (1989) afirma que é, na interação social, que o indivíduo vai se desenvolver, e que a aprendizagem boa é a que se antecipa ao desenvolvimento, que está intimamente relacionado ao contexto sociocultural em que a pessoa está inserida.

[...] o aprendizado desperta vários processos internos de desenvolvimento, que são capazes de operar somente quando a criança interage com pessoas em seu ambiente e quando em cooperação com seus companheiros. Uma vez internalizados, esses processos tornam-se parte das aquisições do desenvolvimento independente da criança. (VYGOTSKY, 1989, p. 101)

Para o psicólogo, é possível compreender o processo de ensino e aprendizagem por meio do conceito de zona de desenvolvimento proximal, em que é muito importante o papel do outro social no desenvolvimento dos indivíduos. Vygotsky (1989) ensina que, além do nível de desenvolvimento real, que se refere àquilo que o sujeito já conquistou e assimilou, existe também o nível de desenvolvimento potencial, que é a capacidade do sujeito de desempenhar suas tarefas com a ajuda de companheiros mais capazes. Existem determinadas tarefas que uma criança não é capaz de realizar sozinha, mas torna-se capaz de realizá-las se alguém der instruções a ela.

O contexto escolar possibilita as atividades coletivas, e o professor, como mediador, tem por objetivo provocar avanços que não ocorreriam espontaneamente, consistindo numa interferência na zona de desenvolvimento proximal.

Geralmente, o aluno não tem condições de percorrer sozinho o caminho do aprendizado. Desse modo, para que ocorra um bom ensino, são muito importantes a instrução e intervenção por parte do professor, bem como a interação entre os alunos. Considerando o favorecimento da aprendizagem de conceitos por meio dessa interação, propomos o trabalho em grupos cooperativos, em que todos os alunos trabalham juntos em um mesmo item das tarefas e as dúvidas são socializadas. 
Em seu trabalho, Costa (2003, p. 11) coloca que "não se trata de agrupar os alunos indiscriminadamente. A proposta aqui é a formação de grupos cooperativos, alicerçados e acordados em princípios éticos, sem os quais é impossível formar o cidadão".

O trabalho cooperativo foi aplicado às aulas na tentativa de se buscar a melhoria do ensino e enfatizar a interação entre professor/aluno e entre os próprios alunos.

Entende-se por grupos co-operativos aqueles cujos trabalhos produtivos são desenvolvidos simultânea e solidariamente por todos os componentes do grupo, todos compromissados com o desenvolvimento não só cognitivo, mas sobretudo com o aspecto social e político de cada um de seus elementos. (COSTA, 2003, p. 13)

A estratégia básica do trabalho em sala de aula é a resolução de problemas em grupos, seguida da discussão com toda a classe, momento em que todos têm a oportunidade de explicar e justificar seus pensamentos, além de compreender as explicações dos outros. Quando um aluno tenta explicar ou justificar algo, ele é levado a reorganizar aquilo que pretende explicar, viabilizando a possibilidade de compreender o assunto em questão.

Os alunos realizaram problemas, os quais, nesta pesquisa, chamamos de problemas ampliados, uma vez que foram retirados de livros didáticos e de notícias de jornais e revistas. Essa ampliação destina-se à inserção dos temas político-sociais propostos na realidade em que vivem e à formação do cidadão, que possa anunciar o caminho para a construção de uma sociedade justa.

Os problemas foram desenvolvidos sob dois aspectos principais: houve os problemas criados com base em um tema político-social e do conteúdo matemático (estatística), e os reenunciados, que tiveram seu enunciado retirado de outras fontes (já citadas anteriormente) e foram ampliados pelos temas político-sociais. Valendo-se da resolução desses problemas, devem-se sistematizar os conteúdos matemáticos, tendo os temas político-sociais como eixos estruturadores para o conteúdo matemático que se pretende estudar.

Trabalhamos com problemas ampliados pelos temas político-sociais, revestidos por questões importantes, de caráter político, social, cultural e ambiental. Com isso, esperamos que a solução dos problemas não pare no simples resultado matemático, mas que o raciocínio possa ser estendido para uma discussão além, envolvendo as questões atuais.

Passaremos a discorrer sobre a pedagogia histórico-crítica, que se enquadra na teoria de aprendizagem e desenvolvimento de Vygotsky (1989), uma vez que compreende a questão educacional com base no desenvolvimento histórico.

A pedagogia histórico-crítica é uma linha pedagógica que vem superar a escola tradicional e a escola nova. Faz, também, crítica às teorias crítico-reprodutivistas porque estas vêem apenas a reprodução, são desvinculadas do aspecto político. Tem o educador brasileiro Dermeval Saviani como principal divulgador e representante desta teoria em nosso país. Saviani (1995, p. 102), com a expressão 'pedagogia histórico-crítica', pretendeu traduzir o "empenho em compreender a questão educacional a partir do desenvolvimento histórico-objetivo".

$\mathrm{Na}$ visão da pedagogia histórico-crítica, a escola é instituição social mediadora entre o conhecimento significativo e o aluno que busca se apropriar do conhecimento clássico. Sua função é socializar o conhecimento acumulado historicamente. 
Uma das preocupações dessa pedagogia é articular a escola com os interesses das camadas populares. Desse modo, a abordagem de temas emergenciais e questões sociais atuais de interesse da sociedade, e, portanto, dos alunos, permite a reflexão dos mesmos e o desenvolvimento de uma consciência crítica, além de possibilitar ao aluno o acesso ao saber elaborado.

Trabalhando com temas político-sociais, estaremos instrumentalizando nossos alunos, para que almejem a transformação da sociedade. Saviani (1999, p. 55-6) coloca que "instrumentalizando os elementos das camadas populares no sentido da assimilação desses conteúdos, eles ganham condições de fazer valer os seus interesses, e é nesse sentido, então, que se fortalecem politicamente".

Partindo de temas político-sociais e, por meio deles, trabalhando o conteúdo matemático, possibilita-se um ensino com significado, contribuindo para uma melhor aprendizagem dos conteúdos clássicos, que irão instrumentalizar o indivíduo a fazer uma leitura da realidade e entender o que nela acontece.

As disciplinas clássicas do currículo são importantes, porém insuficientes para dar conta de questões que angustiam a maioria da população. Após estudo, reflexão e organização de vários educadores, temas diversos como: ética, saúde, orientação sexual, educação ambiental, trabalho e consumo, entre outros, foram incluídos nas grades curriculares, devendo estes impregnar toda a prática educacional e estar presentes nas diferentes áreas curriculares.

Eles recebem o nome de temas transversais e foram propostos pelos PCN, cuja determinação é de que integrem as áreas convencionais e que tenham a mesma importância que elas.

De acordo com Moraes (2003), os temas transversais foram denominados políticosociais porque são questões que envolvem o interesse da sociedade brasileira, e necessitam ser trabalhados em sala de aula. Segundo a autora, os temas “[...] são questões urgentes que interrogam sobre a vida humana, sobre a realidade que está sendo construída, e que demandam não só transformações sociais, como, também, atitudes pessoais [...]" (MORAES, 2003, p. 202).

Busquets (2001) coloca que os temas, que constituem o centro das preocupações sociais, devem ser os eixos longitudinais dos conteúdos escolares:

Se os temas transversais forem tomados como fios condutores dos trabalhos da aula, as matérias curriculares girarão em torno deles; desta forma, transformar-se-ão em valiosos instrumentos que permitirão desenvolver uma série de atividades que, por sua vez, levarão a novos conhecimentos, a propor e resolver problemas, a interrogações e respostas, em relação às finalidades para as quais apontam os temas transversais. (BUSQUETS, 2001, p. 53)

Entendemos que somente com essas duas mudanças de paradigmas - os temas transversais como temas político-sociais e como eixos curriculares - é que, efetivamente, conseguiremos mudanças quanto aos valores da nossa sociedade.

\section{Metodologia}

Com base em procedimentos da pesquisa-ação, este trabalho contou com a interven- 
ção em uma sala de aula por parte da pesquisadora, que retirou, das situações geradas, as observações a respeito de como as questões políticas, sociais, culturais e ambientais estavam incorporadas na prática pedagógica escolar. Segundo Thiollent (2000), pesquisa-ação

[...] é um tipo de pesquisa social com base empírica, que é concebida e realizada em estreita associação com uma ação ou com a resolução de um problema coletivo, e no qual os pesquisadores e os participantes representativos da situação ou do problema estão envolvidos de modo cooperativo ou participativo. (THIOLLENT, 2000, p. 14)

$\mathrm{Na}$ concepção desse autor, a organização da pesquisa deve seguir um planejamento flexível. Deve haver uma fase exploratória (diagnóstico), na qual se delimita o campo de pesquisa e se faz um primeiro levantamento. Depois, procede-se ao planejamento e execução das ações (intervenção), e à análise das mesmas (avaliação).

Criamos e participamos de grupos de discussões, que pudessem retroalimentar nossas ações em sala de aula, e de onde foi possível retirar os encaminhamentos e sugestões para conduzir a pesquisa.

Em nossa participação no projeto Pró-Ciências ${ }^{3}$, tivemos subsídios teóricos e práticos a respeito da importância e eficácia do trabalho com os temas político-sociais. Passamos, então, a ter um espaço para discutir e elaborar os Problemas Ampliados que iríamos propor em nossa sala de aula e, também, para refletir sobre sua aplicação e sobre o efetivo aprendizado dos alunos, que esperávamos acontecer com a inserção do temas político-sociais. Esse grupo de discussão (G1) se reunia semanalmente e era composto de, aproximadamente: trinta professores da rede estadual de ensino, dois professores da rede particular (ouvintes), quatro alunos da Licenciatura em Matemática da Unesp/Bauru, e da professora que orientou esta pesquisa.

$\mathrm{Na}$ escola em que atuávamos, criamos o grupo (G2), onde as reuniões aconteciam semanalmente com os quarenta alunos da oitava série do Ensino Fundamental. Os alunos tinham a oportunidade de colocar os problemas que cada grupo apresentava, bem como as possíveis soluções e as evoluções dos mesmos.

Nesse grupo eram discutidos os problemas ampliados e as resoluções realizadas pelos alunos. Abordamos alguns conceitos matemáticos, como plano cartesiano, escala, construção de gráficos, tipos de gráfico, porcentagem, média aritmética, moda, mediana, área. Esses

\footnotetext{
${ }^{3}$ Projeto da Secretaria Estadual da Educação, em parceria com universidades públicas. Trata-se de um programa de apoio ao aperfeiçoamento de professores de Ensino Médio em Matemática e Ciências, com iniciativa da Capes e da Secretaria Nacional de Ensino e Tecnologia do Ministério da Educação. No estado de São Paulo, é gerenciado pela Fapesp, e tem por objetivo principal o aperfeiçoamento em serviço de professores do Ensino Médio, criando condições aos professores de discutir a importância do significado do trabalho com valores para o ensino e aprendizagem em matemática no Ensino Médio, abordando as implicações que essa proposta traz para a construção de uma realidade educacional transformadora, voltada aos aspectos políticos, sociais e culturais de interesse da sociedade brasileira.
} 
Temas político-sociais no ensino da Matemática

conceitos matemáticos tinham o objetivo de levar os alunos a: ler e interpretar dados estatísticos apresentados por meio de tabelas e gráficos; observar a aplicação dos dados estatísticos no mundo em que vivemos; calcular a porcentagem dos dados estatísticos; construir gráficos para representar os dados de uma pesquisa; diferenciar e utilizar as três medidas de posição: moda, mediana e média aritmética; relacionar a matemática a outras disciplinas; despertar a consciência crítica dos alunos em relação a alguns assuntos importantes (meio ambiente, desigualdade social e impostos), e aprofundar conceitos matemáticos, visando à construção de uma educação transformadora, voltada aos aspectos políticos e sociais de interesse da maioria.

O grupo G3 foi formado em nossa escola e teve a intenção de dar prosseguimento às discussões ocorridas no G1. Era composto por duas professoras de matemática (que também participaram do projeto Pró-Ciências), a coordenadora pedagógica da escola, além da pesquisadora, com o objetivo de discutir nosso trabalho a respeito da adequação das atividades elaboradas à realidade da classe e de buscar sugestões e encaminhamentos para o mesmo.

Formamos o G4, que teve a participação da orientadora desta pesquisa e de suas orientadas, que estavam desenvolvendo seus trabalhos simultaneamente.

As discussões realizadas no G1 serviram de apoio ao G3, onde os trabalhos e as discussões ocorridas eram levados ao G4. O inverso também acontecia, havendo total reciprocidade, e tais discussões fundamentavam o trabalho no G2. Desse modo, ocorria a interligação entre os grupos, assegurando toda a reflexão estabelecida pela pesquisa-ação.

Para levar adiante a pesquisa, utilizamos, como diagnóstico, a prática em que se encontrava o ensino de estatística no Ensino Fundamental. Percebemos, por meio de nossa prática e do convívio com outros professores da rede oficial, que nossos alunos apresentavam grandes dificuldades na aquisição de conceitos, que ocorriam devido ao fato de os conteúdos serem vistos como conhecimentos e valores sociais acumulados e repassados aos alunos.

Lançamos aos alunos da oitava série do Ensino Fundamental questões referentes aos seus valores tanto em relação à escola, quanto a algumas questões político-sociais, pois pretendíamos verificar os resultados do processo de ensino e aprendizagem a que os alunos encontravam-se submetidos.

Como referência, segue uma das atividades que foram trabalhadas em sala de aula:

\section{ATIVIDADE: SALÁRIO}

A tabela a seguir, adaptada e extraída do livro "Para Aprender Matemática"- $8^{a}$ série, de Mori e Onaga (1989, p. 236), apresenta dados sobre os salários dos empregados de uma empresa:

\begin{tabular}{|c|c|}
\hline SALÁRIO (R\$) & NÚMERO DE PESSOAS \\
\hline 2500,00 & 2 \\
\hline 1800,00 & 8 \\
\hline 600,00 & 18 \\
\hline 400,00 & 16 \\
\hline 250,00 & 16 \\
\hline TOTAL & 60 \\
\hline
\end{tabular}


a) Qual é o valor atual do salário-mínimo? $\mathrm{Na}$ opinião do grupo, esse salário é suficiente para suprir as necessidades básicas de um trabalhador?

b) É possível sustentar uma família com esse salário?

c) Pesquisem, nas famílias de cada elemento do grupo, se o salário recebido pelo trabalhador (pai, mãe ou responsável) supre as necessidades básicas da família.

d) Um trabalhador tem gastos mensais com alimentação, moradia, saúde, educação, entre outros itens. O salário-mínimo é suficiente para cobrir essas despesas?

e) Para o grupo, é justo um vereador ter um salário de $\mathrm{R} \$ 2$ 850,00? Por quê?

f) O que deveria ser feito para haver uma melhor distribuição de renda em nosso país?

g) O que é: moda?

mediana?

média aritmética?

h) Dê o valor da moda, mediana e média aritmética dos dados encontrados na tabela. Os valores são iguais?

i) De acordo com as definições e com os valores encontrados, relacione corretamente:

( 1 ) média aritmética

(2) moda

(3) mediana

( ) salário de cerca de metade dos empregados

( ) salário de cada empregado se o dinheiro fosse distribuído igualmente

( ) salário mais comum

Procuramos intervir, por meio de uma ação em que planejamos, elaboramos e aplicamos atividades referentes ao conteúdo estatística, norteada pelos temas político-sociais, em que os alunos trabalharam de modo cooperativo, resolvendo questões, apresentando dúvidas, discutindo e avaliando o trabalho do dia.

O trabalho era socializado para toda a classe no grupão, formado pela professora e pelos alunos da sala, onde todos se reuniam para discutir o trabalho realizado e solucionar dúvidas.

Fizemos, então, a avaliação, ao comparar os dois contextos em que ocorreram o processo ensino e aprendizagem: o contexto anterior, em que os alunos eram submetidos a um ensino que seguia o conteúdo tradicional, e o contexto em que essa mesma turma foi submetida ao trabalho com os problemas ampliados pelos temas político-sociais. Após o trabalho proposto, aplicamos novamente um questionário, em que procuramos verificar as mudanças de desempenho dos alunos em relação à aquisição de conteúdo e, também, a sua posição enquanto cidadão.

Além das estratégias de avaliação citadas, os alunos realizaram uma auto-avaliação, uma avaliação em grupos e uma avaliação do trabalho desenvolvido. 
Temas político-sociais no ensino da Matemática

\section{Resultados e discussão}

Em um primeiro momento, lançamos questionários referentes aos valores dos alunos, bem como a respeito de sua vivência na escola, de seu relacionamento com a comunidade escolar, e de como a disciplina os auxilia a um melhor entendimento da realidade brasileira.

Foi possível a inclusão do trabalho com valores no ensino da matemática por meio das discussões ocorridas envolvendo os temas político-sociais. Essa inclusão teve como objetivo a construção da democracia e da cidadania com base em conteúdos vinculados aos interesses da maioria da população. Nesse sentido, Oliveira (2001, p. 20) destaca que

[...] o trabalho educativo deve sempre servir à humanização do homem, isto é, deve ser sempre um trabalho valorado positivamente, um trabalho dirigido por valores, estará em princípio sempre buscando contribuir para que a participação do indivíduo, na sociedade, seja aquela que torne essa sociedade cada vez mais humanitária.

No decorrer do bimestre, aplicamos atividades referentes ao conteúdo estatística (problemas criados, reenunciados e ampliados pelos temas político-sociais), e, ao finalizar, aplicamos um novo questionário para analisar todo o processo e verificar se esta abordagem interferiu no desenvolvimento dos alunos quanto à aquisição do conteúdo e quanto à sua postura no contexto social em que vivem. Em relação à aprendizagem de conceitos matemáticos, podemos afirmar que, quando os alunos perceberam que estávamos debatendo, em sala de aula, os assuntos que afligem a sociedade brasileira e, conseqüentemente, eles próprios, ocorreu o aumento do interesse e da motivação dos alunos, facilitando a assimilação na aprendizagem da matemática e dos diversos assuntos propostos.

A seguir, para confirmar as afirmações anteriores, apresentaremos os depoimentos:

"As discussões feitas no primeiro bimestre me despertaram para que possamos ver o que acontece no mundo de hoje e para que possamos mostrar para nossos pais o que estudamos na escola. Fez eu aprender mais, fez a gente participar das atividades na classe, fez todos nós aprender como se respeitar e fez a gente saber mais sobre as coisas [...]". (sic)

'[...] Comparando o modo como a matemática era trabalhada com o modo que trabalhamos agora, considero que melhorei o modo como eu via tudo, melhorei a convivência e, agora, sei a importância da matemática no mundo". (sic)

"As aulas eram boas, com muita aprendizagem. Os professores nos ensinavam a matemática exata (geometria, contas e mais contas). Agora, nós aprendemos matemática aprendendo outros assuntos, como politico e social do país. As aulas eram cansativas, mas agora não e aprendi mais sobre o meu país estudando matemática. Todas as discussões me despertaram para a realidade do país e do mundo na atualidade..." (sic) 
Concluímos que o processo de ensino e aprendizagem vivenciados pelos alunos propiciou condições para que manifestassem seus pontos de vista, suas formas de raciocínio e suas hipóteses. É possível constatar esses fatos por meio do relato de um participante da pesquisa: "Falo com meus pais sobre a escola e eles acham que, com esse projeto que nos estávamos, eu aprendi mais coisa, eles direm que eu antes não discutia os problemas que existem dentro e fora de casa, mas agora eu discuto". (sic)

Analisando o questionário e a auto-avaliação que realizaram, pudemos concluir que o trabalho contribuiu para despertar a criticidade dos alunos e, também, para romper com a falta de consciência dos problemas político-sociais à qual os alunos encontravam-se submetidos. Foi possível detectar melhora no aprendizado dos conceitos matemáticos por meio das avaliações por eles realizadas e na reunião de final de bimestre, em que o professor de cada disciplina atribui uma nota a cada aluno. Por ser uma classe com a qual já havíamos trabalhado no ano anterior, percebemos que os conceitos foram satisfatórios ao abordar a matemática por meio dos temas político-sociais.

\section{Conclusão}

Para termos um ensino de matemática que leve à formação do indivíduo comprometido com os aspectos políticos, sociais, culturais e ambientais da sociedade em que vive, devemos colocar o aluno em contato com estes aspectos e evitarmos as aulas somente expositivas, com definições e aplicações de fórmulas e exercícios.

Neste trabalho, tivemos a intenção de despertar o interesse dos alunos pela matemática, incorporando os conteúdos aos aspectos acima citados. Trabalhamos, então, com os temas político-sociais porque sua presença, na escola, torna-se muito importante para a construção de uma realidade educacional transformadora, uma vez que enfoca os aspectos de interesse atual da sociedade. Porém, o trabalho com os temas político-sociais será viabilizado se eles sofrerem uma mudança de paradigma, constituindo-se em eixos longitudinais do currículo, como centros de interesse, e, com isso, contribuir para a formação de uma consciência crítica dos alunos.

De acordo com os resultados encontrados, podemos concluir que a mudança de eixo proposta por este trabalho foi favorável ao aprendizado dos alunos e que, desta maneira, a matemática lhes pareceu muito mais agradável, sendo possível uma melhor aquisição do conteúdo e, conseqüentemente, uma melhoria do rendimento. Perante seus comportamentos frente às atividades desenvolvidas, verificamos que as discussões foram válidas e que foi possível despertar a criticidade dos alunos, que perceberam os problemas emergenciais de nossa sociedade, por meio dos temas político-sociais, havendo, em grande maioria, mudança de postura frente aos seus valores. 
Temas político-sociais no ensino da Matemática

\section{Referências}

BRASIL. Ministério da Educação e do Desporto. Secretaria da Educação Fundamental. Parâmetros Curriculares Nacionais: terceiro e quarto ciclos - apresentação dos temas transversais. Brasília: MEC/SEF, 1998.

BUSQUETS, M. D. et al. Temas transversais em Educação: bases para uma formação integral. 6. ed. São Paulo: Ática, 2001.

COSTA, L. Q. Um jogo em grupos co-operativos: alternativa para a construção do conceito de números inteiros e para a abordagem dos conteúdos - procedimentos, condutas e normas. 2003. 179f. Tese (Doutorado em Educação) - Faculdade de Educação, Unicamp, Campinas, 2003.

MORAES, M. S. S. et al. Temas político-sociais/transversais na educação brasileira: o discurso visa à transformação social? Ciência Geográfica, Bauru, v. 9, n. 2, p. 199-204, 2003.

MORI, I.; ONAGA, D. S. Para aprender matemática: $8^{a}$ série. 1. ed. São Paulo: Editora Saraiva, 1989.

OLIVEIRA, B. Valores e o ensino de matemática. Presidente Prudente: Unesp, 2001. 21p. (apostila digitada)

SAVIANI, D. Escola e democracia. 32. ed. Campinas: Autores Associados, 1999. (Polêmicas do Nosso Tempo).

. Pedagogia histórico-crítica: primeiras aproximações. 5. ed. Campinas: Autores Associados, 1995. (Polêmicas do Nosso Tempo).

THIOLLENT, M. Metodologia da pesquisa-ação. 10. ed. São Paulo: Cortez, 2000.

VYGOTSKY, L. S. Interação entre aprendizado e desenvolvimento. In: . A formação social da mente. Trad. José Cipolla Neto, Luis S. M. Barreto, Solange C. Afeche. 3. ed. São Paulo: Martins Fontes, 1989. p. 89-103. (Psicologia e Pedagogia). 